OPEN ACCESS

Edited by:

Fernando Cendes,

Campinas State University, Brazil

Reviewed by:

Jose F. Tellez-Zenteno,

University of Saskatchewan, Canada

*Correspondence:

Josef Finstere

fifigs1@yahoo.de

Specialty section:

This article was submitted to

Epilepsy,

a section of the journal

Frontiers in Neurology

Received: 04 June 2019

Accepted: 27 August 2019

Published: 21 October 2019

Citation:

Finsterer J (2019) Commentary: Epilepsy in Leigh Syndrome With

Mitochondrial DNA Mutations.

Front. Neurol. 10:973.

doi: 10.3389/fneur.2019.00973

\section{Commentary: Epilepsy in Leigh Syndrome With Mitochondrial DNA Mutations}

\author{
Josef Finsterer * \\ Krankenanstalt Rudolfstiftung, Messerli Institute, Vienna, Austria
}

Keywords: Leigh syndrome, epilepsy, mtDNA, oxidative phosphorylation, anti-seizure drugs, respiratory chain

\section{A Commentary on}

Epilepsy in Leigh Syndrome With Mitochondrial DNA Mutations

by Lee, S., Na, J. H., and Lee, Y. M. (2019). Front. Neurol. 10:496. doi: 10.3389/fneur.2019.00496

With interest we read the article by Lee et al. about 25 patients with Leigh syndrome (LS) due to various mtDNA variants of whom 14 had epilepsy (1). We have the following comments and concerns.

A main shortcoming of the study is that heteroplasmy rates of the mtDNA variants were not provided. It is also not mentioned if mtDNA was extracted from blood lymphocytes, muscle, or from other tissues. Knowing heteroplasmy rates in various tissues is crucial as it may be one of the factors determining the phenotype and outcome.

LS may not only be due to mtDNA variants but also due to nDNA variants. We should be informed about which nDNA variants were found in the 100 patients who did not carry an mtDNA variant.

A shortcoming of the study is the absence of a comprehensive family history. We should know how many mothers of the 25 included patients were clinically affected or carried the mtDNA variant of their son. We should also know if there were other first degree relatives with epilepsy or phenotypic features of a mitochondrial disorder (MID). According to Table 1 the family history was negative for epilepsy in all 25 patients. This is quite unusual in the light that $75 \%$ of the MIDs due to mtDNA variants are maternally inherited (2).

In the abstract 14 of 25 patients had epilepsy but in the results section and Table 1 only $32 \%$ of the 25 patients had seizures (1). The authors should explain this discrepancy.

We should be informed why only 12 of the 14 patients with epilepsy received a treatment with anti-seizure drugs (ASDs). We should also know if the two patients without ASDs were seizure-free or if they or their parents refused ASD therapy.

We should know if the two patients on a ketogenic diet (KD) were the ones who did not receive ASD treatment. It should be mentioned if the KD was effective and reduced seizure frequency in the two patients on $\mathrm{KD}$ as has been previously reported (3).

Rarely, patients with LS may develop stroke-like episodes (SLEs) (4) of which the stroke-like lesion (SLL) is the morphological equivalent on imaging (5). We should know in how many of the 14 patients with epilepsy, epilepsy or seizures were associated with a SLE, since seizures may trigger SLEs and vice versa.

Interestingly, the authors mention that $>50 \%$ of the 125 patients received ophthalmologic treatment (1). It should be indicted if patients had pigmentary retinopathy, glaucoma, cataract, optic atrophy, refractory errors, megalocornea, iris atrophy, pupillary dysfunction, cataract, ciliary body epithelial dysfunction, macular degeneration, retinal hypertrophy, choroidal atrophy, or corneal ulcers and conjunctivitis, frequently found in MID patients (6). 
LS is frequently a disease with poor prognosis (7). Since mean follow-up duration was 5.7 years it is quite likely that some of the initially included 25 patients had deceased during follow-up. Thus, we should be informed how many of the 25 died during follow-up and which were the causes of death. According to Table 1, one third of the patients had cardiac and one third had pulmonary involvement, which may significantly contribute to mortality of these patients.

\section{REFERENCES}

1. Lee S, Na JH, Lee YM. Epilepsy in Leigh syndrome with mitochondrial DNA mutations. Front Neurol. (2019) 10:496. doi: 10.3389/fneur.2019.00496

2. Poulton J, Finsterer J, Yu-Wai-Man P. Genetic counselling for maternally inherited mitochondrial disorders. Mol Diagn Ther. (2017) 21:419-29. doi: 10.1007/s40291-017-0279-7

3. Kang HC, Lee YM, Kim HD, Lee JS, Slama A. Safe and effective use of the ketogenic diet in children with epilepsy and mitochondrial respiratory chain complex defects. Epilepsia. (2007) 48:82-8. doi: 10.1111/j.1528-1167.2006.00906.x

4. Morin C, Dubé J, Robinson BH, Lacroix J, Michaud J, De Braekeleer $\mathrm{M}$, et al. Stroke-like episodes in autosomal recessive cytochrome oxidase deficiency. Ann Neurol. (1999) 45:389-92. doi: 10.1002/15318249(199903)45:3<389::AID-ANA16>3.0.CO;2-B

5. Finsterer J. Mitochondrial metabolic stroke: phenotype and genetics of strokelike episodes. J Neurol Sci. (2019) 400:135-41. doi: 10.1016/j.jns.2019.03.021
Overall, the study could be more meaningful if the various shortcomings were solved and if more data about family history, multiorgan involvement, mutation load, and outcome were provided.

\section{AUTHOR CONTRIBUTIONS}

JF contributed to the design, literature search, discussion, first draft, and critical comments.

6. Finsterer J, Zarrouk-Mahjoub S. Ophthalmologic involvement in mitochondrial disorders. Ophthalm Genet. (2017) 38:298. doi: 10.1080/13816810.2016.1199714

7. Finsterer J. Leigh and Leigh-like syndrome in children and adults. Pediatr Neurol. (2008) 39:223-35. doi: 10.1016/j.pediatrneurol.2008. 07.013

Conflict of Interest Statement: The author declares that the research was conducted in the absence of any commercial or financial relationships that could be construed as a potential conflict of interest.

Copyright (C) 2019 Finsterer. This is an open-access article distributed under the terms of the Creative Commons Attribution License (CC BY). The use, distribution or reproduction in other forums is permitted, provided the original author(s) and the copyright owner(s) are credited and that the original publication in this journal is cited, in accordance with accepted academic practice. No use, distribution or reproduction is permitted which does not comply with these terms. 